\title{
Estimating the Value of Public Insurance Using Complementary Private Insurance
}

\author{
Marika Cabral and Mark R. Cullen \\ ONLINE APPENDIX
}

\section{A Proof of Proposition 2}

Proposition 2. Suppose an individual's utility can be represented by the increasing, thrice differentiable function $u(c)$. Define $\pi(w, \theta, \gamma \mid \varphi)$ as: $E[u(w+(1-\theta) x-\pi(w, \theta, \gamma \mid \varphi))]=E[u(w+(1-\gamma) x)]$, where $\theta>\gamma$ and the expectation is taken over $x \leq 0$, representing the uncertain losses the individual faces. Additionally, suppose the individual is risk averse and his/her utility exhibits weakly decreasing absolute risk aversion. Then,

$$
\pi(w, \alpha, 0 \mid \varphi) \geq \frac{\alpha}{\delta} \pi(w, \alpha+\delta, \alpha \mid \varphi)
$$

and thus we obtain the bound in Corollary 1.

Proof. Based on Lemma 1 below, we complete the proof by demonstrating: (i) $\frac{\partial}{\partial \theta}\left(\frac{\pi(w, \theta, \gamma \mid \varphi)}{\theta-\gamma}\right) \leq 0$, and (ii) $\frac{\partial}{\partial \gamma}\left(\frac{\pi(w, \theta, \gamma \mid \varphi)}{\theta-\gamma}\right) \leq 0$.

proof of $(i)$ :

Let $z \equiv w+(1-\gamma) x$ and $y \equiv-\pi(w, \theta, \gamma \mid \varphi)-(\theta-\gamma) x$. Define a function $F(\beta)=E u(z+\beta y)-E u(z){ }^{1}$ Obviously, $F(0)=0$. By definition of $\pi(w, \theta, \gamma \mid \varphi)$, we know that $F(1)=0$.

We want to show that

$$
\frac{\partial}{\partial \theta}\left(\frac{\pi(w, \theta, \gamma \mid \varphi)}{\theta-\gamma}\right) \leq 0
$$

Note that this is equivalent to,

$$
\frac{\pi(w, \theta, \gamma \mid \varphi)}{\theta-\gamma} \geq \frac{\partial}{\partial \theta} \pi(w, \theta, \gamma \mid \varphi)=\frac{-E x u^{\prime}(w+(1-\theta) x-\pi(w, \theta, \gamma \mid \varphi))}{E u^{\prime}(w+(1-\theta) x-\pi(w, \theta, \gamma \mid \varphi))}
$$

Re-writing this condition we get:

$$
E\left[(\pi(w, \theta, \gamma \mid \varphi)+(\theta-\gamma) x) u^{\prime}(w+(1-\theta) x-\pi(w, \theta, \gamma \mid \varphi))\right] \geq 0
$$

Substituting in the definitions above we get:

$$
E\left[-y u^{\prime}(z+y)\right]=-F^{\prime}(1) \geq 0
$$

Under risk aversion, $\mathrm{F}$ is concave. Because $F(0)=F(1)=0$, we know that $F^{\prime}(1) \leq 0$, and thus the above condition holds.

proof of (ii):

Let $z \equiv w+(1-\gamma) x-(\theta-\gamma) x-\pi(w, \theta, \gamma \mid \varphi)$ and $y \equiv \pi(w, \theta, \gamma \mid \varphi)+(\theta-\gamma) x$. Define a function $F(\beta)=$ $E u(z+\beta y)-E u(z)$. Obviously, $F(0)=0$. By definition of $\pi(w, \theta, \gamma \mid \varphi)$, we know that $F(1)=0$.

We want to show that:

$$
\frac{\partial}{\partial \gamma}\left(\frac{\pi(w, \theta, \gamma \mid \varphi)}{\theta-\gamma}\right) \leq 0
$$

\footnotetext{
${ }^{1}$ The technique used for this part of the proof draws upon a similar technique used in Eeckhoudt and Gollier (2001).
} 
Note that this is equivalent to,

$$
\frac{\pi(w, \theta, \gamma \mid \varphi)}{\theta-\gamma} \leq-\frac{\partial}{\partial \gamma} \pi(w, \theta, \gamma \mid \varphi)=\frac{-E x u^{\prime}(w+(1-\gamma) x)}{E u^{\prime}(w+(1-\theta) x-\pi(w, \theta, \gamma \mid \varphi))}
$$

Let us re-write this as follows:

$$
\pi(w, \theta, \gamma \mid \varphi) E u^{\prime}(w+(1-\theta) x-\pi(w, \theta, \gamma \mid \varphi))+(\theta-\gamma) E x u^{\prime}(w+(1-\gamma) x) \leq 0
$$

Because the individual's utility exhibits weakly decreasing absolute risk aversion, we know by Lemma 2 below that: $E u^{\prime}(w+(1-\gamma) x) \geq E u^{\prime}(w+(1-\theta) x-\pi(w, \theta, \gamma \mid \varphi))$. So, the LHS of the above is bounded above

$$
\pi(w, \theta, \gamma \mid \varphi) E u^{\prime}(w+(1-\theta) x-\pi(w, \theta, \gamma \mid \varphi))+(\theta-\gamma) E x u^{\prime}(w+(1-\gamma) x) \leq E\left[(\pi(w, \theta, \gamma \mid \varphi)+(\theta-\gamma) x) u^{\prime}(w+(1-\gamma) x)\right] .
$$

Re-writing the RHS term using the above definitions,

$$
E\left[(\pi(w, \theta, \gamma \mid \varphi)+(\theta-\gamma) x) u^{\prime}(w+(1-\gamma) x)\right]=E\left[y u^{\prime}(z+y)\right]=F^{\prime}(1) .
$$

Under risk aversion, $\mathrm{F}$ is concave. Because $F(0)=F(1)=0$, we know that $F^{\prime}(1) \leq 0$.

Lemma 1. Suppose (i) $\frac{\partial}{\partial \theta}\left(\frac{\pi(w, \theta, \gamma \mid \varphi)}{\theta-\gamma}\right) \leq 0$, and (ii) $\frac{\partial}{\partial \gamma}\left(\frac{\pi(w, \theta, \gamma \mid \varphi)}{\theta-\gamma}\right) \leq 0$.

Then,

$$
\text { [a] } \quad \pi(w, \alpha, 0 \mid \varphi) \geq \frac{\alpha}{\delta} \pi(w, \alpha+\delta, \alpha \mid \varphi), \quad \text { and } \quad[\mathrm{b}] \quad \pi(w, \alpha+\delta, 0 \mid \varphi) \geq \frac{\alpha+\delta}{\delta} \pi(w, \alpha+\delta, \alpha \mid \varphi)
$$

Proof. Under the assumptions, we get the following:

$$
\frac{\pi(w, \theta, \gamma \mid \varphi)}{\theta-\gamma} \geq \frac{\pi(w, \theta+\epsilon, \gamma \mid \varphi)}{\theta+\epsilon-\gamma} \geq \frac{\pi(w, \theta+\epsilon, \gamma+\mu \mid \varphi)}{\theta+\epsilon-(\gamma+\mu)}
$$

where the first inequality follows from assumption (i) and the second from assumption (ii). This holds for all $\mu, \epsilon \geq 0$. Evaluating this at $\mu=\theta-\gamma, \theta=\alpha, \gamma=0$, and $\epsilon=\delta$ gives result [a] and result [b].

Lemma 2. If $u(c)$ exhibits weakly decreasing absolute risk aversion, then $E u^{\prime}(w+(1-\gamma) x) \geq E u^{\prime}(w+(1-$ $\theta) x-\pi(w, \theta, \gamma \mid \varphi))$.

Proof. Weakly decreasing absolute risk aversion means,

$$
\frac{\partial}{\partial c}\left(\frac{-u^{\prime \prime}(c)}{u^{\prime}(c)}\right) \leq 0
$$

This is equivalent to,

$$
\frac{-u^{\prime} u^{\prime \prime \prime}+\left(u^{\prime \prime}\right)^{2}}{\left(u^{\prime}\right)^{2}} \leq 0
$$

Multiplying both sides by $\frac{u^{\prime}}{u^{\prime \prime}}(\leq 0)$ and rearranging terms we get:

$$
\frac{-u^{\prime \prime \prime}}{u^{\prime \prime}} \geq \frac{-u^{\prime \prime}}{u^{\prime}}
$$

Notice that $v=-u^{\prime}$ is a valid utility function as it is increasing in $c$. Since we know this holds for all c, $-u^{\prime}$ is more risk averse than $u$, and thus we can represent $-u^{\prime}$ as an increasing concave transformation of $u$ : $-u^{\prime}=\phi(u)$.

The result then follows from showing that the distribution of $u(w+(1-\theta) x-\pi(w, \theta, \gamma \mid \varphi))$ second order stochastically dominates the distribution of $u(w+(1-\gamma) x)$ (and thus every concave utility function, including $\phi$, prefers it). Consider two distributions, $F_{A}(z)$ and $F_{B}(z)$ with the same mean. Suppose these distributions 
are defined over a finite domain $[\underline{z}, \bar{z}]$, where $F_{A}(\underline{z})=F_{B}(\underline{z})=0$ and $F_{A}(\bar{z})=F_{B}(\bar{z})=1$. Showing $F_{A}(z)$ second order stochastically dominates $F_{B}(z)$ is equivalent to showing:

$$
\int_{\underline{z}}^{y}\left[F_{A}(z)-F_{B}(z)\right] d z \leq 0, \quad \forall y \in\{\underline{z}, \bar{z}\} .
$$

Applying this to our context, we want to show:

$$
\int_{\underline{z}}^{y}\left[F_{x}\left(\frac{u^{-1}(z)-w+\pi(w, \theta, \gamma \mid \varphi)}{1-\theta}\right)-F_{x}\left(\frac{u^{-1}(z)-w}{1-\gamma}\right)\right] d z \leq 0, \quad \forall y \in\{\underline{z}, \bar{z}\} .
$$

It is easy to show that the cumulative density functions cross exactly once at the point $z^{*}=u\left(w+\frac{1-\gamma}{\gamma-\theta} \pi(w, \theta, \gamma \mid \varphi)\right)$ :

$$
\begin{array}{ll}
F_{x}\left(\frac{u^{-1}(z)-w+\pi(w, \theta, \gamma \mid \varphi)}{1-\theta}\right)-F_{x}\left(\frac{u^{-1}(z)-w}{1-\gamma}\right) \leq 0 & \forall z \in\left\{\underline{z}, z^{*}\right\}, \\
F_{x}\left(\frac{u^{-1}(z)-w+\pi(w, \theta, \gamma \mid \varphi)}{1-\theta}\right)-F_{x}\left(\frac{u^{-1}(z)-w}{1-\gamma}\right) \geq 0 & \forall z \in\left\{z^{*}, \bar{z}\right\} .
\end{array}
$$

Thus, we know that $\int_{\underline{z}}^{y}\left[F_{x}\left(\frac{u^{-1}(z)-w+\pi(w, \theta, \gamma \mid \varphi)}{1-\theta}\right)-F_{x}\left(\frac{u^{-1}(z)-w}{1-\gamma}\right)\right] d z \leq 0, \quad \forall y \in\left\{\underline{z}, z^{*}\right\}$. In addition, it is straightforward to show that the fact that the distributions have the same means $(E u(w+(1-\gamma) x)=$ $E u(w+(1-\theta) x-\pi(w, \theta, \gamma \mid \varphi)))$ implies that $\int_{\underline{z}}^{\bar{z}}\left[F_{x}\left(\frac{u^{-1}(z)-w+\pi(w, \theta, \gamma \mid \varphi)}{1-\theta}\right)-F_{x}\left(\frac{u^{-1}(z)-w}{1-\gamma}\right)\right] d z=0$. Thus, it must be the case that $\int_{\underline{z}}^{y}\left[F_{x}\left(\frac{u^{-1}(z)-w+\pi(w, \theta, \gamma \mid \varphi)}{1-\theta}\right)-F_{x}\left(\frac{u^{-1}(z)-w}{1-\gamma}\right)\right] d z \leq 0, \quad \forall y \in\{\underline{z}, \bar{z}\}$.

\section{B Numerical Example}

We consider a numerical example to compare the bounding approach to a more structural approach that specifies all the underlying primitives to illustrate the trade-offs between these complementary approaches more concretely. Consider an individual indexed by $\varphi$ who faces some potential loss and has compulsory public insurance that covers 60 percent of this risk. Further, suppose the individual has the option to purchase private supplemental insurance to cover an additional 10 percent of the risk on top of the public insurance. Supposing that the conditions within Proposition 1 hold, the individual's willingness-to-pay for the inframarginal coverage is at least six times his/her willingness-to-pay for the supplemental coverage, and thus the individual's surplus associated with the inframarginal coverage is at least six times the surplus associated with the supplemental coverage. This bound is applicable regardless of the distribution of uncertainty, the specific form of utility, and access to liquidity.

Suppose we observe (or have a reliable estimate for) an individual's willingness-to-pay for supplemental insurance and the expected cost associated with this insurance. For a given willingness-to-pay for supplemental insurance, Table A1 reports the calibrated value of the inframarginal coverage under various assumptions on the underlying utility function, liquidity, and risk. For each scenario considered, the table also displays the surplus ratio, which we define as the ratio of the surplus from the inframarginal coverage under the stated assumptions to the lower bound on surplus from the inframarginal coverage derived under Proposition 1 (surplus ratio $\left.=\frac{\pi(w, \alpha, 0 \mid \varphi)-c(w, \alpha, 0 \mid \varphi)}{\operatorname{Bound}(\pi(w, \alpha, 0 \mid \varphi)-c(w, \alpha, 0 \mid \varphi))}\right)$. The surplus ratio describes how tight the lower bound is under a given set of assumptions, with a smaller ratio indicating a tighter bound. To ease comparisons across the sets of assumptions, each distribution of risk we consider has the same expected cost: $\$ 8$ for each 1 percentage point of insurance coverage.

Fixing the willingness-to-pay for supplemental insurance at \$100, Figure A1 displays the numerical analogue of Figure 2 under the range of assumptions considered in Table A1. Specifically, this figure displays the marginal cost and marginal valuation of insurance generosity on the intensive margin, where units are scaled to represent dollars per 1 percentage point of insurance coverage. Given a willingness-to-pay for supplemental insurance of $\$ 100$, an (under)estimate of the individual's mean marginal valuation of insurance for a 1 percentage point increase in coverage is $\$ 10$ over the range $\theta \in[0.6,0.7]$. Based on Proposition 1 , the lower bound on the individual's valuation of the inframarginal 60 percent coverage is $\$ 600(\pi(w, 0.6,0 \mid \varphi) \geq 6 \times \pi(w, 0.7,0.6 \mid \varphi))$ 
and the lower bound on the net surplus from the inframarginal coverage is $\$ 120$ (Area ABCD in Figure A1). For each of the considered sets of assumptions in Table A1 and the associated calibrated parameters, this figure displays the implied marginal willingness-to-pay for insurance on the intensive margin.

Figure A1 and Table A1 illustrate two important points. First, the precise implied valuation for the inframarginal public coverage is very sensitive to the underlying assumptions on the form of the utility, liquidity, and the nature of uncertainty. Comparing the associated values in Table A1 columns (2) and (3) when $\pi(w, 0.7,0.6 \mid \varphi)=\$ 100$, we see that the implied net surplus from public coverage is 40 percent higher under the CRRA specification than under the CARA specification, with the same assumed risk and benchmark income. Comparing Table A1 columns (2), (4), (6), and (8), we see that the implied net surplus from public coverage varies greatly with changes in the assumed risk distribution, even conditional on specifying the same form of utility, benchmark income, and expected cost. A comparison of columns (2), (10) and (11) reveals that the implied valuation of public coverage is very sensitive to the benchmark income; in this example, when $\pi(w, 0.7,0.6 \mid \varphi)=\$ 100$, the implied net surplus from public coverage based on CRRA utility increases 71 percent when the benchmark income is cut by $\$ 14.5 \mathrm{~K}$. Second, the lower bound can be quite conservative, and the tightness of the lower bound depends on the underlying risk, utility, and liquidity. Across all the considered scenarios, we see that the implied surplus associated with inframarginal public coverage ranges from 1.79 to 6.29 times the lower bound. ${ }^{2}$ This highlights an important limitation of the bounding approach: it provides less precise information about welfare than an approach that fully specifies the underlying primitives.

In summary, this numerical example highlights the central trade-off between these complementary approaches to quantifying welfare. The bounding approach is more robust than a more structural approach in terms of perturbations in the underlying utility, risk distribution, and liquidity; however, this robustness comes at the cost of obtaining a lower bound on welfare rather than a precise welfare number. In some applications, this cost may be considerable if the lower bound is too loose to provide valuable insights.

\section{Non-Parametric Bound on Value of Supplemental Insurance}

In principle, one could use the observed data points to construct a coarse non-parametric lower bound on the mean willingness-to-pay for supplemental insurance and hence a fully non-parametric lower bound on the mean willingness-to-pay for the inframarginal compulsory insurance. In practice, this fully non-parametric bound would be very loose and largely uninformative in many settings with limited premium variation, including the empirical application in this paper. Drawing on the data in Table 1 in the text, there are roughly two observed points in the demand for Plan H relative to Plan M: 2003 with a high relative price $(P=0.163$ percent annual earnings, $Q=60.3$ percent) and 2004-2006 with a stable lower relative price (on average, $P=0.109$ percent annual earnings, $\mathrm{Q}=64.4$ percent). Suppose individuals in the population are ordered from highest willingness-to-pay for supplemental insurance to lowest willingness-to-pay for supplemental insurance on the unit interval, $[0,1]$. While our approach relies on estimating a parametric demand curve for supplemental insurance, it is possible to construct a very coarse fully non-parametric lower bound on the willingness-to-pay for supplemental coverage using these two data points, by assigning the lower bound on willingness-to-pay of 0.163 percent for individuals in [0, 0.603], 0.109 percent for individuals in $(0.603,0.644]$, and 0 for individuals in $(0.644,1]$. This gives us a non-parametric lower bound on the mean willingness-to-pay for the supplemental insurance across the sample population of 0.103 percent of annual earnings. Note that this bound on the mean willingness-to-pay is roughly equal to the mean cost of coverage in this setting. While the precise measure of costs depends on the assumptions used to project costs for truncated spells, this bound is slightly lower than our most conservative measure of costs (0.111 percent of annual earnings) and above our least conservative measure of costs ( 0.069 percent of annual earnings). This bound is not particularly informative in this setting and the non-parametric bound is very loose for all the common demand forms we analyze (e.g., linear, $\log -\log$, linear-log, logit, etc). In other words, given the observed limited range of premium variation, the nonparametric bound provides a poor approximation of the surplus generated by supplemental insurance based on common demand forms and thus leads to a largely uninformative fully non-parametric bound on the value of the inframarginal coverage in this setting. This motivates our baseline approach which is to construct the inframarginal welfare bound based an estimated parametric demand curve for supplemental insurance and to investigate robustness to alternative common demand forms.

\footnotetext{
${ }^{2}$ Appendix Figure A2 depicts how the surplus ratio varies with the generosity of the baseline coverage, fixing the underlying utility parameters as calibrated under the assumptions analyzed in Figure A1.
} 


\section{Moral Hazard and Selection: Estimates and Robustness}

As discussed in the paper, the data and environment has both strengths and weaknesses in terms of capturing the costs associated with disability. A strength of the empirical environment is that there is individual-level administrative cost data. While in principle one could use the very same price variation used to estimate the demand curves to estimate moral hazard and selection, a practical limitation is that it is difficult to obtain precise estimates of selection and moral hazard within the context of disability insurance because realized costs are noisy proxies for expected costs given the low incidence of disability. In the face of these strengths and weaknesses, we take the following approach. First, our baseline welfare analysis focuses on estimating welfare in the status quo allocation of insurance. Since this estimation draws on observed realized costs, this analysis fully incorporates moral hazard and selection within the status quo insurance allocation. Second, we analyze welfare within counterfactuals that depart from the status quo allocation of insurance under a wide range of assumptions on the moral hazard elasticity. The counterfactuals we focus on do not require estimating the degree of selection. Overall, we find that the key lessons of the counterfactual welfare analysis are not very sensitive to the amount of incremental moral hazard within a plausible range of elasticities.

While our baseline welfare analysis does not depend on estimating moral hazard or selection, here we present estimates of moral hazard and selection leveraging the available price variation. As noted in the text, there is limited statistical power for these analyses, so they should be interpreted with this caveat in mind.

Moral Hazard Let $c_{i t}$ represent the present discounted value of the realized costs relative to annual earnings associated with providing individual $i$ in year $t$ an incremental 10 percent replacement rate paid in the event of disability. ${ }^{3}$ We investigate the possibility of moral hazard by estimating the following reduced form equation:

$$
c_{i t}=\beta_{0}+\beta_{1}\left(p_{i t}^{H}-p_{i t}^{M}\right)+\beta_{2} p_{i t}^{M}+\lambda X_{i t}+\epsilon_{i t},
$$

where $\left(p_{i t}^{H}-p_{i t}^{M}\right)$ and $p_{i t}^{M}$ are the relative prices of Plan $\mathrm{H}$ and Plan $\mathrm{M}$, respectively. The demand results reveal that the demand for Plan $\mathrm{H}$ coverage and Plan $\mathrm{M}$ coverage are both responsive to the respective relative prices. Thus, the test for moral hazard is then a test on whether lower relative prices (and thus more people on more generous coverage) lead to higher claims. In addition to estimating the reduced form specification described above, we also estimate the analogous instrumental variables (IV) specification where we estimate the relationship between costs and the share of people with Plan $\mathrm{H}$ and Plan M coverage, instrumenting these shares with the variation in relative prices.

Table A3 Panel A displays these estimates. Across all the specifications, the estimates are statistically indistinguishable from zero, consistent with the incremental disability coverage inducing no moral hazard in this setting. Note that while the estimates are consistent with no moral hazard associated with the incremental coverage, the estimates are not very precise. This lack of precision is not surprising, given the low incidence of disability claims and the range of variation exploited in this IV strategy.

Selection As discussed in the paper, our baseline analysis investigates welfare under the status quo allocation of insurance and thus does not require estimating the degree of selection. Additionally, the counterfactual analysis considers an extension of the compulsory insurance to include the supplemental coverage relative to a setting in which no one has the supplemental coverage, which again does not require estimating the degree of selection. Nevertheless, below we investigate selection in this setting for completeness.

Table 4 Panel B in the text displays the mean cost scaled to represent a 10 percent replacement rate (the mean value of $c_{i t}$ ) for everyone in the estimation sample and separately for those who do and do not purchase the incremental coverage. Note that the mean relative price for Plan $\mathrm{H}$ is very close to the average cost of those individuals willing to pay for the incremental coverage. In other words, the predicted competitive equilibrium in the market for the incremental coverage would be close to the observed pair of average prices and quantities regardless of the shape of the average and marginal cost curves far outside of the variation in the data. Thus, we can think of the observed mean (relative) costs of the insured and quantity of individuals insured as an approximation of the competitive equilibrium for the incremental coverage, which allows us to interpret the welfare measures describing the status quo allocation of supplemental insurance as approximating that of a competitive equilibrium for supplemental insurance.

\footnotetext{
${ }^{3}$ Recall that we use an interest rate of 4 percent in the baseline estimation.
} 
While mean costs in the status quo are an approximation of the costs in a competitive equilibrium, we can use alternative methods to predict counterfactual mean costs in a competitive market and demonstrate that these yield similar estimates. For instance, one way to measure selection in this setting is to use the price variation used to estimate demand to trace out the marginal and average cost curves of the insurer, using the Einav and Finkelstein (2011) approach. Alternatively, another way one could measure selection in this setting would be to assume there is no moral hazard and thus bring in another moment on the cost curve, the average costs of insuring everyone under Plan $\mathrm{H}$ (the mean value of $c_{i t}$ for the population if there is no moral hazard). Comparing these approaches, the former approach leverages variation in costs among those marginal to the price variation in the data, while the latter approach provides a measure of global selection in this population. Figure A3 plots the average and marginal costs curves obtained from each of these approaches. (Table A3 Panel B column (1) reports the underlying point estimates for the approach leveraging the marginal price variation.) There are at least two things to note in this figure. First, we obtain very similar cost curves representing selection regardless of which method we use to measure selection in this setting. Second, regardless of the shape of the average and marginal cost curves far outside of the variation in the data, the observed average price and quantity across the sample period are close to the predicted competitive equilibrium using either set of cost curves.

\section{E Additional Demand Estimates}

As discussed in the text, the main estimation focuses on the demand for Plan $\mathrm{H}$ over Plan $\mathrm{M}$ because most of the premium variation in this context is in the relative premium for Plan H over Plan M. However, in addition to our main estimates on the demand for Plan $\mathrm{H}$ relative to Plan $\mathrm{M}$, we also investigate the demand for Plan $\mathrm{M}$ relative to Plan L coverage to provide suggestive evidence on the validity of Assumption 1. To do this, we use the limited variation in the (relative) premium for Plan M compared to Plan L to estimate the demand for Plan M coverage. Specifically, we estimate the relative demand for Plan M by estimating the following equation:

$$
\text { PlanMor } H_{i t}=I\left(r_{\pi}(0.6,0.5 \mid \varphi) \geq p_{i t}^{M}\right)=\theta_{0}+\theta_{1} p_{i t}^{M}+\phi X_{i t}+e_{i t},
$$

where PlanMor $H_{i}$ indicates that the individual chose Plan $\mathrm{H}$ or Plan M coverage and $p_{i t}^{M}$ is the price of Plan $\mathrm{M}$ relative to Plan $\mathrm{L}$ (as $p_{i t}^{L}=0$ ).

Table A4 displays the Plan M demand estimates as well as the baseline Plan $\mathrm{H}$ demand estimates for reference. There are two important things to note about the Plan $\mathrm{M}$ demand estimates as compared to analogous estimates for Plan H coverage. First, while the negative premium coefficient estimates in Panel A columns (3) and (4) suggest that the demand for the incremental coverage provided by Plan M is price-sensitive, the coefficient estimates and the corresponding mean implied willingness-to-pay for coverage are much less precisely estimated than the analogous estimates for Plan H coverage. The difference in precision across these estimates is not surprising given the limited variation in Plan M premiums during the sample period relative to the variation in the Plan $\mathrm{H}$ premium (see Table 1). Second, though the Plan M demand estimates are statistically imprecise, the general pattern of the mean implied willingness-to-pay estimates is consistent with the assumption we use to derive a lower bound on the total welfare (Assumption 1). Assumption 1 implies that an individual's willingness-to-pay for incremental coverage is decreasing in the replacement rate of the baseline coverage, and thus an individual's willingness-to-pay for the incremental coverage provided by Plan $\mathrm{M}$ relative to Plan L is weakly greater than his/her willingness-to-pay for the incremental coverage provided by Plan $\mathrm{H}$ relative to Plan M. ${ }^{4}$ Consistent with this assumption, the estimate for the mean willingness-to-pay for Plan M (relative to Plan L) is higher than the estimated mean willingness-to-pay for Plan H (relative to Plan M), though the Plan M estimates are imprecise enough that these estimates are not statistically distinct. While the baseline welfare analysis in the text uses the more precise (and more conservative) Plan $\mathrm{H}$ demand estimates, Appendix G reports the analogous welfare measures based on the Plan M demand estimates for comparison.

\section{F Supplemental Insurance Value - Numerical Example}

Based on our the analysis in Table 5 Panel B, the mean willingness-to-pay for the incremental 10 percent coverage moving from a 60 percent to a 70 percent replacement rate is between 2.8 times the mean cost of the

\footnotetext{
${ }^{4}$ Under Assumption 1 used to calculate the welfare bound (from Proposition 1), $\pi(w, \alpha+\delta, \alpha \mid \varphi)$ is decreasing in $\alpha$.
} 
coverage (if there is no moral hazard) and 1.8 times the mean cost of the coverage (if moral hazard is in range of prior estimates). Because of the long tail of risk associated with lost earnings from disability, the estimated mean willingness-to-pay for the incremental coverage may be consistent with risk aversion in the typical range found in the prior literature. Below, we present a simple, stylized calibration illustrating this point.

Consider an individual that is 45 years old. We consider a 20 year lifetime horizon, over which time the individual would continue working until 65 years of age if not disabled. Suppose this individual faces the empirical distribution of disability incidence in the sample population, where disability spells censored at five years are assumed to represent an absorbing state for the remainder of the individual's life. In the sample population, 0.3 percent of active employees begin a long term disability claim in a given year, and the median disability claim results in more than two years of lost income. For simplicity, this calibration considers uncertainty in injuries/illness that result in disability which originate during the one year time horizon for which the LTD coverage applies. In this stylized calibration, an individual's lifetime utility is the sum of the annual expected utility across the 20 year lifetime horizon we consider, where utility is not discounted across periods and individuals can costlessly save and borrow. ${ }^{5}$ The calibration considers a CARA utility specification to facilitate comparisons with estimates in the recent literature estimating risk preferences from insurance decisions. ${ }^{6}$

We consider a range of values for the willingness-to-pay for supplemental insurance, spanning roughly 2 times to 3 times the cost of providing the incremental coverage. For each value, Table A2 presents the calibrated utility parameters to match this value as well as the implied willingness-to-pay for the compulsory public coverage based on these calibrated parameters. Across the range of values for the willingness-to-pay for supplemental insurance, the calibrated risk aversion parameter ranges from $3.57 \times 10^{-5}$ to $5.69 \times 10^{-5}$. These calibrated risk aversion parameters are broadly within the range of prior estimates of risk aversion in the literature, even at the low end of this range. For instance, Cohen and Einav (2007) estimate a mean CARA parameter of $6.7 \times 10^{-3}$ in the setting of auto insurance, Handel (2013) estimates a mean CARA parameter of $2.32 \times 10^{-4}$ in the setting of health insurance, and Handel and Kolstad (2015) estimate a mean CARA parameter of $8.6 \times 10^{-5}$ in the setting of health insurance. In other words, typical values of risk aversion in the literature are broadly consistent with the mean willingness-to-pay value we estimate for the incremental LTD coverage in the empirical application.

While this simple, stylized calibration reveals that the estimates are broadly consistent with the range of risk aversion values typically estimated in the literature, we note that a more realistic calibration would incorporate important aspects that could matter in reality such as correlated risks, credit constraints, state dependence, other margins for adjustment (e.g., spousal labor supply), etc. Given that a key feature of the approach we outline in the text is that specifying these underlying primitives is unnecessary, a fully developed calibration model is outside the scope of the analysis in this paper. Nevertheless, it is reassuring that the qualitative findings are broadly consistent with the qualitative findings in the prior literature that analyzes the value of disability insurance based on rich calibrated life-cycle models (e.g., Low and Pistaferri (2015), Chandra and Samwick (2005)).

\section{G Additional Robustness Analysis}

In addition to the robustness analysis presented in the text, we examine the robustness of the results to additional alternative specifications. Table A5 displays the results of this additional analysis. Panel A displays the implied lower bound on the value of public coverage based on the alternative specifications, and Panel B displays the underlying regression estimates for the alternative specifications. Each row represents the results of a distinct specification. For reference, row (1) displays the baseline estimates and implied welfare bounds (based on Table 4 Panel A column (1)). Rows (2) through (4) display the estimates and implied welfare bounds using alternative specifications of the cost measures. The baseline analysis uses the present discounted value of costs using an interest rate of 4 percent, where we use the maximum potential duration for spells censored at five years (as described in the text). Row (2) displays an alternative specification where costs are measured only through the first five years following the year of disability onset (the years for which we have complete claims data). This specification yields a less conservative bound than the baseline analysis. Rows (3) and (4) display

\footnotetext{
${ }^{5}$ Note that the utility specification within this stylized dynamic calibration has no direct analogue to the assumptions within Proposition 2 which considers a static utility specification. In practice, the broader assumptions within Proposition 1 are empirically satisfied within the scenarios considered in the calibration.

${ }^{6}$ This simple calibration abstracts from the elimination period feature of the disability plans available at this firm.
} 
specifications where costs are defined as the present discounted value of the maximum potential duration for truncated spells, using alternative interest rates to calculate the present discounted value. Comparing these specifications to the baseline estimates, we see that the analysis is not very sensitive to the chosen discount rate within a range of reasonable interest rates.

The baseline welfare analysis utilizes the demand for Plan $\mathrm{H}$, estimated based on the variation described in Table 1. Leveraging the modest amount of variation in Plan M premiums, we can repeat the welfare analysis using the implied Plan M demand curve. Table A5 row (5) displays an alternative specification that relies on the Plan $\mathrm{M}$ demand estimates. As discussed above, the implied mean valuation of Plan $\mathrm{M}$ exceeds that of Plan $\mathrm{H}$, so this alternative specification provides a less conservative lower bound on the value of disability coverage. However, as discussed above, the relatively small amount of variation in Plan M premiums limits the statistical precision of welfare analysis based on the Plan M estimates as compared to the baseline welfare analysis which leverages the Plan H estimates.

\section{H Tax Treatment of Premiums and Benefits}

For the LTD plans offered at this employer, premiums are paid by employees with pre-tax dollars, and the benefits individuals receive from their LTD policy in the event of a disability are taxable. In contrast, SSDI benefits are largely exempt from tax. Because it is not clear that employees know the differential tax treatment of each of these, premiums and the benefits are treated symmetrically in the baseline specification. Robustness analysis reported in the text explores an alternative specification that reflects the tax treatment of premiums and benefits, where we assume LTD premiums are paid with pre-tax dollars, LTD benefits individuals receive are taxable, and public SSDI benefits are not taxable (effectively raising the mean SSDI replacement rate from 34 percent to 52 percent). For simplicity, we assume that the same marginal tax rate is applicable to premiums and benefits, and we use a marginal tax rate of 35 percent, roughly the average marginal tax rate among individuals in this sample accounting for state and federal income taxes. While accounting for the tax treatment of LTD premiums and benefits leads to a lower implied surplus for a fixed extension of LTD coverage, accounting for the tax treatment of public SSDI benefits (and the effectively higher after-tax replacement rate) exactly offsets this giving us the same lower bound on the welfare of public disability insurance as in the baseline specification. To see this, suppose that individuals face a constant marginal tax rate $\tau$. In addition, suppose that compulsory public insurance benefits are not taxable and LTD benefits are taxable. Let WelfareExtn $(10 \times(1-\tau))$ denote the estimated welfare associated with a $(10 \times(1-\tau))$ percentage point increase in the disability replacement rate of compulsory government insurance (relative to no incremental coverage) given that LTD premiums are paid with pre-tax dollars and the marginal tax rate is $\tau$. To account for the tax treatment of premiums, the mean willingness-to-pay should be scaled down by $(1-\tau)$ relative to the baseline estimates if the tax treatment is salient to consumers, and the baseline estimates for the government's costs should be symmetrically scaled down by $(1-\tau)$ to reflect costs associated with the incremental coverage net of tax revenue. Thus, it is easy to see that accounting for taxation leads the welfare associated with a $(10 \times(1-\tau))$ percentage point extension of the replacement rate of government provided disability coverage to be a scaled version of the baseline estimates of an extension not accounting for the tax treatment: Welfare $\operatorname{Extn}_{\tau}(10 \times(1-\tau))=(1-\tau)$ WelfareExtn ${ }_{0}(10)$. The lower bound on the value of government provided coverage is unchanged. To see this, let $W$ elfarePublic $(\alpha, \tau)$ represent the welfare associated with the inframarginal public coverage accounting for the tax rate $\tau$ and the public insurance is of generosity $\alpha$. Assuming public benefits are tax-exempt, it is easy to show that the lower bound on welfare is invariant to accounting for the tax treatment: $\{$ Lower bound on WelfarePublic $(\alpha, \tau)\}=\alpha \frac{\text { WelfareExtn }(10 \times(1-\tau))}{10 \times(1-\tau)}=$ $\alpha \frac{(1-\tau) W e l f a r e E x t n_{0}(10)}{10 \times(1-\tau)}=\alpha \frac{\text { WelfareExtn } n_{0}(10)}{10}=\{$ Lower bound on WelfarePublic $(\alpha, 0)\}$. 


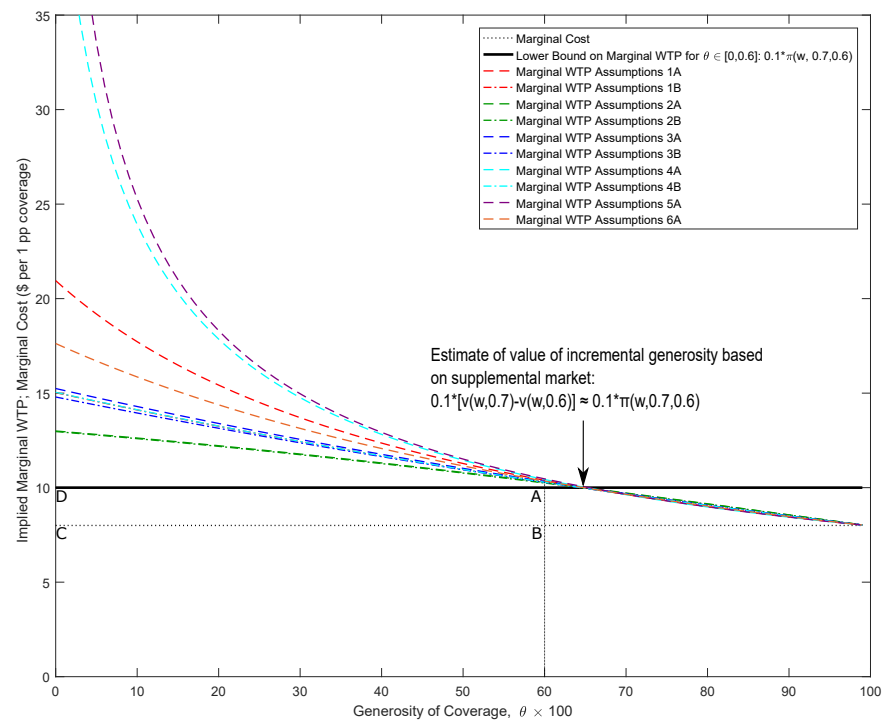

Figure A1: Numerical Example

Notes: Fixing the willingness-to-pay for supplemental insurance at $\$ 100$, this figure displays the numerical analogue of Figure 2 under the range of assumptions considered in Table A1. Specifically, this figure considers an individual indexed by $\varphi$ and displays the individual's marginal cost and marginal valuation of insurance generosity on the intensive margin, where units are scaled to represents dollars per 1 percentage point of insurance coverage. Given the willingness-to-pay for supplemental insurance is $\$ 100$, an (under)estimate of the individual's mean marginal valuation of insurance for a 1 percentage point increase in coverage is $\$ 10$ over the range $\theta \in[0.6,0.7]$. Based on Proposition 1 , the lower bound on the individual's valuation of the coverage is $\$ 600(\pi(w, 0.6,0 \mid \varphi) \geq 6 \times \pi(w, 0.7,0.6 \mid \varphi))$ and the lower bound on the net surplus from the inframarginal coverage is \$120 (Area ABCD in this figure). Under each of the considered sets of assumptions in Table A1, this figure displays the implied marginal willingness-to-pay for insurance on the intensive margin based on the parameters calibrated to match the willingness-to-pay for supplemental insurance. 


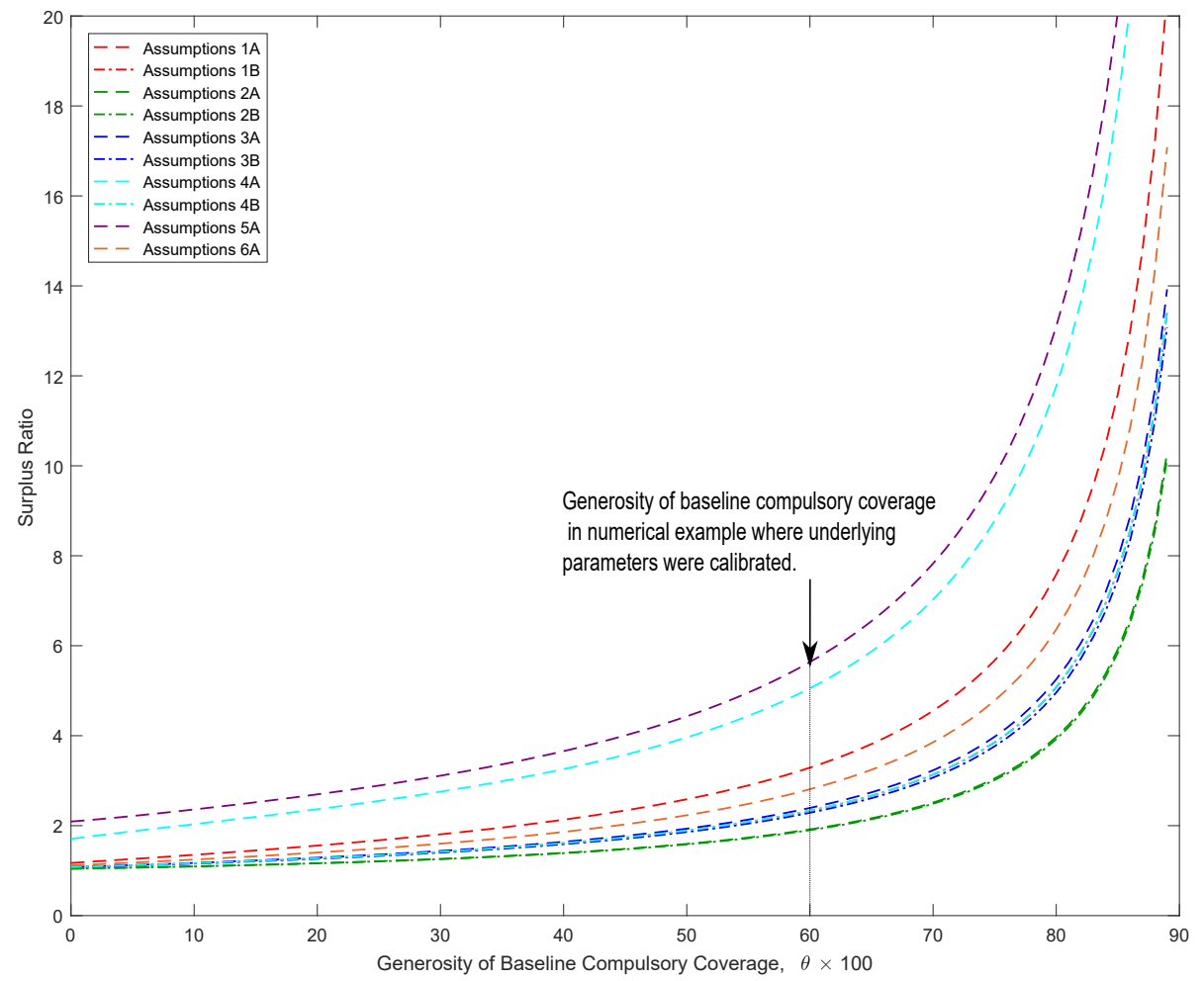

Figure A2: Numerical Example: Surplus Ratio and Baseline Coverage Generosity

Notes: This figure displays the surplus ratio (defined in the text) as the baseline coverage generosity varies, holding the underlying parameters fixed based on the calibration depicted in Figure A1 and Table A1. 


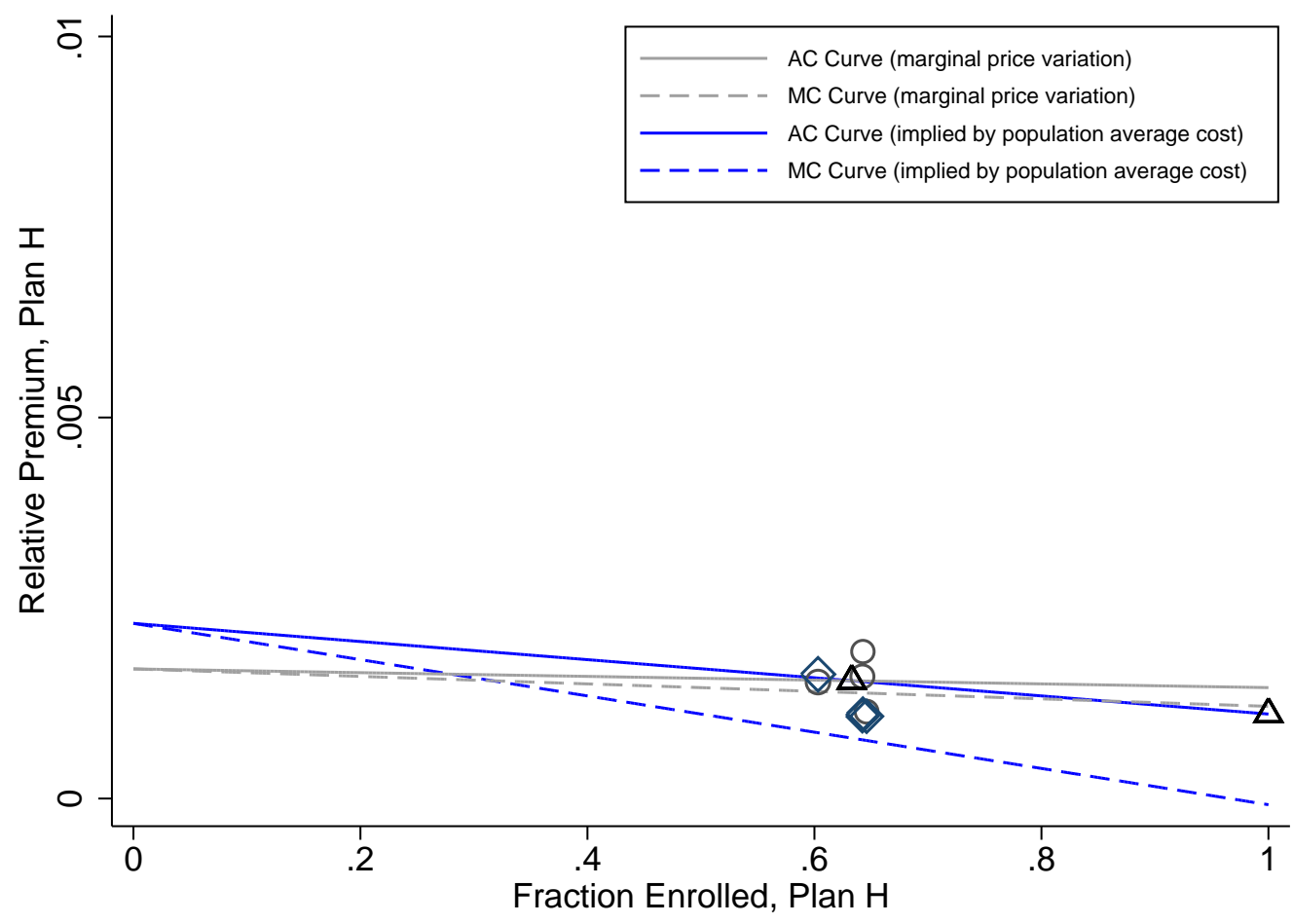

Figure A3: Selection: Alternative Estimation Approaches

Notes: This table displays linear cost curves associated with Plan H coverage, where the curves are inferred using two different methods. The first method for estimating the average and marginal cost curves follows Einav and Finkelstein (2011) and uses variation in prices and the induced variation in the fraction of the population with Plan $\mathrm{H}$ coverage to trace out how the average expected cost of those on Plan $\mathrm{H}$ varies. The second method for inferring the average and marginal cost curves is to assume there is no moral hazard and interpolate between the average cost if the whole population were insured and the average cost of the actual insured population. These approaches are represented in the figure by the gray and blue lines, respectively. The gray circles represent the mean costs by year for those with Plan H coverage; the black triangles represent the mean costs of those with Plan $\mathrm{H}$ and everyone in the population, pooling data across the entire sample period. The blue diamonds represent the observed pairs of Plan $\mathrm{H}$ premium and enrollment by year (the variation used to estimate demand). 
Table A1: Numerical Example

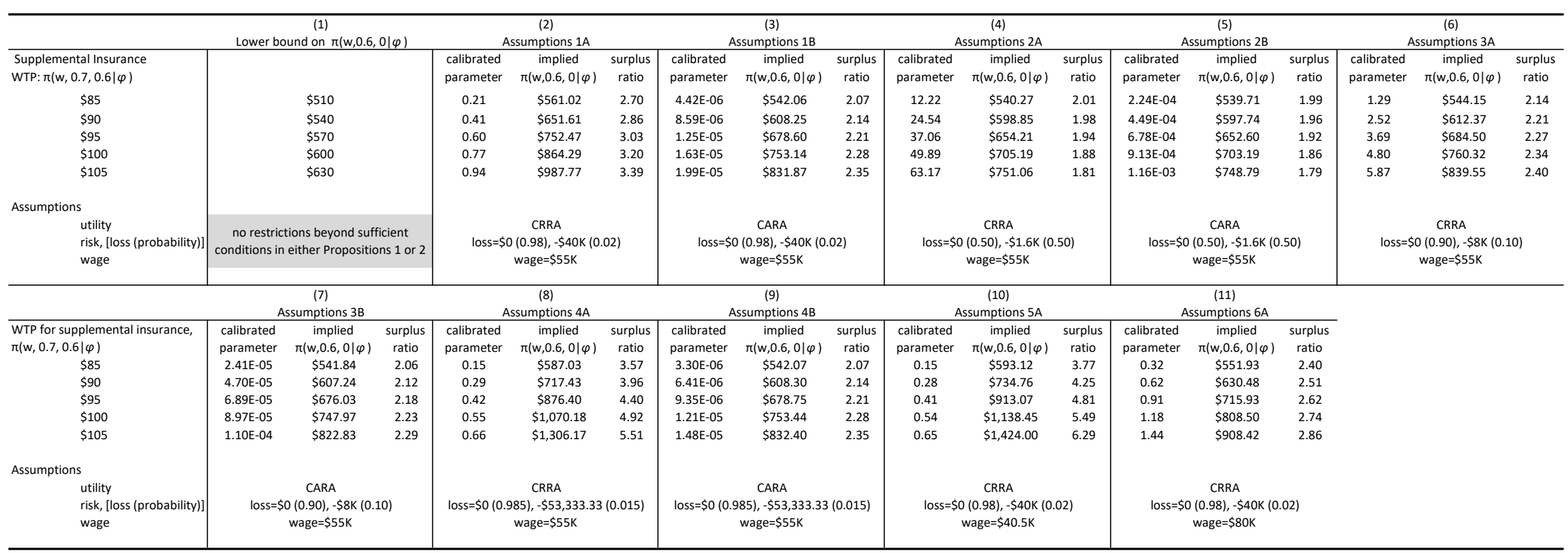

Notes: The above table describes a numerical example which compares the bounding approach described in the text to a more structural analysis that defines a particular utility function and distribution of risk Consider an individual indexed by $\varphi$ who faces some potential loss and has compulsory public insurance that covers $60 \%$ of this risk. Further, suppose the individual has the option to purchase private supplemental insurance to cover an additional $10 \%$ of the risk on top of the public insurance. Following the definitions in the text, let $\pi(w, 0.6,0 \mid \varphi)$ represent the individual's willingness-to-pay for compulsory public insurance relative to no insurance, and let $\pi(w, 0.7,0.6 \mid \varphi)$ represent the individual's willingness-to-pay for supplemental insurance to top-up the compulsory public insurance. Suppose the individual's demand/preferences satisfy the sufficient condition in either Proposition 1 or 2 , we get a lower bound on $\pi(w, 0.6,0 \mid \varphi)$ for any given observed $\pi(w, 0.7,0.6 \mid \varphi)$. This bound is applicable regardless of the distribution of uncertainty the individual faces and regardless of what form the utility takes. To contrast this bound with an approach that specifies more of the underlying primitives, the table displays the implied value of $\pi(w, 0.6,0 \mid \varphi)$ given a value of $\pi(w, 0.7,0.6 \mid \varphi)$ under various assumptions. Specifically, for each set of assumptions and each value of the willingness-to-pay for supplemental coverage $(\pi(w, 0.7,0.6 \mid \varphi))$, Table A1 reports the calibrated utility parameters to match this willingness-to-pay for supplemental insurance and the implied willingness-to-pay for the inframarginal coverage, $\pi(w, 0.6,0 \mid \varphi)$, based on these calibrated parameters. the inframarginal coverage derived under Proposition 1 (surplus ratio $=\frac{\pi(w, 0.6,0 \mid \varphi)-c(w, 0.6,0 \mid \varphi)}{\operatorname{Bound}(\pi(w, 0,6,0 \mid \varphi)-c(w, 0.6,0 \mid \varphi))}$ ). The surplus ratio describes how tight the lower bound is under a given set of assumptions, with a smaller ratio indicating a tighter bound. Taking the case of $\pi(w, 0.7,0.6 \mid \varphi)=\$ 100$, Figure A1 plots numerical analogue of Figure 2 under the sets of assumptions described in this table. 
Table A2: Stylized Calibration

\begin{tabular}{|c|c|c|c|}
\hline & & $\begin{array}{c}\text { (2) } \\
\text { Calibration }\end{array}$ & \\
\hline $\begin{array}{l}\text { Supplemental Insurance } \\
\text { WTP: } \pi(w, 0.7,0.6)\end{array}$ & $\begin{array}{l}\text { calibrated } \\
\text { parameter }\end{array}$ & $\begin{array}{c}\text { implied } \\
\pi(w, 0.34,0)\end{array}$ & surplus ratio \\
\hline$\$ 200$ & 3.57E-05 & $\$ 1,797$ & 2.64 \\
\hline$\$ 225$ & 4.20E-05 & $\$ 2,449$ & 3.20 \\
\hline$\$ 250$ & 4.75E-05 & $\$ 3,231$ & 3.80 \\
\hline$\$ 275$ & $5.24 \mathrm{E}-05$ & $\$ 4,151$ & 4.44 \\
\hline$\$ 300$ & $5.69 \mathrm{E}-05$ & $\$ 5,213$ & 5.11 \\
\hline Assumptions & & & \\
\hline utility & \multicolumn{3}{|c|}{ CARA } \\
\hline risk & \multicolumn{3}{|c|}{ empirical distribution } \\
\hline wage & \multicolumn{3}{|c|}{$\$ 65 \mathrm{k}$} \\
\hline mean costs for $10 \%$ rep rate & \multicolumn{3}{|c|}{106.44} \\
\hline
\end{tabular}

Notes: This is a stylized calibration considering an individual that is 45 years of age. We consider a 20 year time horizon, where the individual would continue working until age 65 if not disabled. Suppose this individual faces the empirical distribution of disability incidence in the sample population, where disability spells censored at five years are assumed to represent an absorbing state for the remainder of the individual's life. For simplicity, this calibration considers uncertainty in injuries/illness that result in disability which originate during the one year time horizon for which the LTD coverage applies. In this stylized calibration, an individual's lifetime utility is the sum of the annual expected CARA utility across the 20 year lifetime horizon we consider, where utility is not discounted across periods and individuals can costlessly save and borrow. 
Table A3: Moral Hazard and Selection

\begin{tabular}{|c|c|c|c|c|c|c|c|c|}
\hline \multicolumn{9}{|c|}{$\begin{array}{ll} & \text { Panel A: Moral Hazard } \\
\end{array}$} \\
\hline & \multicolumn{4}{|c|}{ Realized Costs of All Employees (2SLS) } & \multicolumn{4}{|c|}{ Realized Costs of All Employees (Reduced Form) } \\
\hline & $\begin{array}{l}\text { Costs } \\
\text { (1) }\end{array}$ & $\begin{array}{l}\text { Costs } \\
\text { (2) }\end{array}$ & $\begin{array}{c}\text { I(LTD Claim) } \\
\text { (3) }\end{array}$ & $\begin{array}{c}\text { I(LTD Claim) } \\
\text { (4) }\end{array}$ & $\begin{array}{l}\text { Costs } \\
(5)\end{array}$ & $\begin{array}{c}\text { Costs } \\
(6) \\
\end{array}$ & $\begin{array}{c}\text { I(LTD Claim) } \\
(7)\end{array}$ & $\begin{array}{c}\text { I(LTD Claim) } \\
(8)\end{array}$ \\
\hline Plan $\mathrm{H}$ & $\begin{array}{l}-0.0071 \\
(0.0105)\end{array}$ & $\begin{array}{c}0.0024 \\
(0.0236)\end{array}$ & $\begin{array}{l}-0.0339 \\
(0.0201)\end{array}$ & $\begin{array}{l}-0.0358 \\
(0.0375)\end{array}$ & & & & \\
\hline PlanMorH & $\begin{array}{l}-0.0155 \\
(0.0190)\end{array}$ & $\begin{array}{l}-0.0530 \\
(0.0844)\end{array}$ & $\begin{array}{l}-0.0599 \\
(0.0414)\end{array}$ & $\begin{array}{l}-0.0524 \\
(0.1590)\end{array}$ & & & & \\
\hline Relative Premium Plan $\mathrm{H}$ & & & & & $\begin{array}{c}0.16 \\
(0.58)\end{array}$ & $\begin{array}{c}0.03 \\
(1.22)\end{array}$ & $\begin{array}{c}1.10 \\
(0.97)\end{array}$ & $\begin{array}{c}2.57 \\
(1.94)\end{array}$ \\
\hline Premium Plan M & & & & & $\begin{array}{c}3.41 \\
(3.57)\end{array}$ & $\begin{array}{c}4.08 \\
(5.15)\end{array}$ & $\begin{array}{l}13.11 \\
(6.78)\end{array}$ & $\begin{array}{c}5.44 \\
(10.15)\end{array}$ \\
\hline Constant & $\begin{array}{c}0.0180 \\
(0.0197)\end{array}$ & $\begin{array}{c}0.0427 \\
(0.0582)\end{array}$ & $\begin{array}{c}0.0724 \\
(0.0397)\end{array}$ & $\begin{array}{c}0.0675 \\
(0.1120)\end{array}$ & $\begin{array}{l}-0.0044 \\
(0.0057)\end{array}$ & $\begin{array}{c}-0.0052 \\
(0.0068)\end{array}$ & $\begin{array}{c}-0.0184 \\
(0.0106)\end{array}$ & $\begin{array}{c}-0.0092 \\
(0.0137)\end{array}$ \\
\hline Time Trend Included & & $\mathrm{x}$ & & $x$ & & $x$ & & $x$ \\
\hline \multicolumn{9}{|l|}{ Dep Var } \\
\hline Mean & 0.0011 & 0.0011 & 0.0032 & 0.0032 & 0.0011 & 0.0011 & 0.0032 & 0.0032 \\
\hline SD & 0.0302 & 0.0302 & 0.0561 & 0.0561 & 0.0302 & 0.0302 & 0.0561 & 0.0561 \\
\hline N & 47,884 & 47,884 & 47,884 & 47,884 & 47,884 & 47,884 & 47,884 & 47,884 \\
\hline \multicolumn{9}{|c|}{$\begin{array}{l}\text { Panel B: Selection } \\
\end{array}$} \\
\hline & \multicolumn{4}{|c|}{ Realized Cost of Employees on Plan $\mathrm{H}$} & \multicolumn{4}{|c|}{ Realized Cost of Employees on Plan M or Plan $\mathrm{H}$} \\
\hline & $\begin{array}{l}\text { Costs } \\
(1)\end{array}$ & $\begin{array}{c}\text { Costs } \\
(2)\end{array}$ & $\begin{array}{c}\text { I(LTD Claim) } \\
\text { (3) }\end{array}$ & $\begin{array}{c}\text { I(LTD Claim) } \\
(4)\end{array}$ & $\begin{array}{c}\text { Costs } \\
(5)\end{array}$ & $\begin{array}{c}\text { Costs } \\
(6)\end{array}$ & $\begin{array}{c}\text { I(LTD Claim) } \\
(7) \\
\end{array}$ & $\begin{array}{c}\text { I(LTD Claim) } \\
(8) \\
\end{array}$ \\
\hline Relative Premium Plan $\mathrm{H}$ & $\begin{array}{c}0.018 \\
(0.839)\end{array}$ & $\begin{array}{c}0.609 \\
(1.486)\end{array}$ & $\begin{array}{c}1.110 \\
(1.580)\end{array}$ & $\begin{array}{c}3.738 \\
(2.374)\end{array}$ & & & & \\
\hline Premium Plan M & & & & & $\begin{array}{c}4.529 \\
(4.327)\end{array}$ & $\begin{array}{c}4.154 \\
(5.397)\end{array}$ & $\begin{array}{l}13.490 \\
(8.075)\end{array}$ & $\begin{array}{l}15.020 \\
(9.981)\end{array}$ \\
\hline Constant & $\begin{array}{c}0.002 \\
(0.001)\end{array}$ & $\begin{array}{c}0.001 \\
(0.002)\end{array}$ & $\begin{array}{c}0.003 \\
(0.002)\end{array}$ & $\begin{array}{l}-0.002 \\
(0.003)\end{array}$ & $\begin{array}{l}-0.006 \\
(0.007)\end{array}$ & $\begin{array}{l}-0.005 \\
(0.008)\end{array}$ & $\begin{array}{l}-0.017 \\
(0.012)\end{array}$ & $\begin{array}{l}-0.019 \\
(0.015)\end{array}$ \\
\hline Time Trend Included & & $x$ & & $x$ & & $x$ & & $x$ \\
\hline Dep Var & & & & & & & & \\
\hline Mean & 0.0015 & 0.0015 & 0.0041 & 0.0041 & 0.0013 & 0.0013 & 0.0037 & 0.0037 \\
\hline SD & 0.0358 & 0.0358 & 0.0636 & 0.0636 & 0.0329 & 0.0329 & 0.0606 & 0.0606 \\
\hline N & 30,306 & 30,306 & 30,306 & 30,306 & 38,227 & 38,227 & 38,227 & 38,227 \\
\hline
\end{tabular}

Notes: This table displays the moral hazard and selection estimates which leverage the premium variation for LTD plans. Panel A displays the results related to moral hazard, where columns (1) through (4) display the IV results and columns (5) through (8) display the reduced form results. Panel B displays the selection estimates, where columns (1) through (4) focus on selection into Plan H. In addition, columns (5) through (8) focus on selection into at least Plan M coverage (relative to Plan L) leveraging the modest amount of variation Plan M premiums. The outcome variables considered in these regressions are two different cost measures: the present discounted value of costs (relative to annual earnings) incurred using the maximum potential duration for truncated spells as described in the text ("Costs", the baseline cost measure used in the text), and an indicator for having any LTD claim ("I(LTD Claim)"). 
Table A4: Demand and Cost Estimates: Comparing Plan H and Plan M

\begin{tabular}{|c|c|c|c|c|}
\hline \multicolumn{5}{|c|}{ Panel A: Demand Estimates } \\
\hline & $\begin{array}{c}\text { Plan } \mathrm{H} \\
(1)\end{array}$ & $\begin{array}{l}\text { Plan } \mathrm{H} \\
\text { (2) }\end{array}$ & $\begin{array}{c}\text { PlanMorH } \\
\text { (3) }\end{array}$ & $\begin{array}{c}\text { PlanMorH } \\
(4)\end{array}$ \\
\hline Relative premium Plan $\mathrm{H}$ & $\begin{array}{l}-71.26 \\
(11.77)\end{array}$ & $\begin{array}{l}-64.93 \\
(12.21)\end{array}$ & & \\
\hline \multicolumn{5}{|l|}{ Ln (relative premium Plan $\mathrm{H}$ ) } \\
\hline (Relative) premium Plan M & & & $\begin{array}{c}-91.19 \\
(38.30)\end{array}$ & $\begin{array}{l}-38.15 \\
(35.34)\end{array}$ \\
\hline Constant & $\begin{array}{c}0.72 \\
(0.03)\end{array}$ & $\begin{array}{c}0.70 \\
(0.02)\end{array}$ & $\begin{array}{l}0.95 \\
(0.06)\end{array}$ & $\begin{array}{l}0.87 \\
(0.05)\end{array}$ \\
\hline \multicolumn{5}{|l|}{ Controls } \\
\hline Time Trend & $\mathrm{x}$ & $\mathrm{x}$ & $\mathrm{x}$ & $\mathrm{x}$ \\
\hline Individual Fixed Effects & & $x$ & & $x$ \\
\hline \multicolumn{5}{|l|}{ Dep Var } \\
\hline Mean & 0.63 & 0.63 & 0.80 & 0.80 \\
\hline Std dev & 0.48 & 0.48 & 0.40 & 0.40 \\
\hline $\mathrm{N}$ & 47,884 & 47,884 & 47,884 & 47,884 \\
\hline \multicolumn{5}{|l|}{$\begin{array}{l}\text { Implied Mean WTP for Incremental Coverage, \$/annual } \\
\text { earnings }\end{array}$} \\
\hline Estimate & 0.00310 & 0.00328 & 0.00481 & 0.00936 \\
\hline Std Error & $(0.00032)$ & $(0.00034)$ & $(0.02792)$ & (3.75262) \\
\hline \multicolumn{5}{|c|}{ Panel B: Mean Costs } \\
\hline & \multicolumn{2}{|c|}{ Plan $\mathrm{H}$} & \multicolumn{2}{|c|}{ PlanMorH } \\
\hline & Mean & Std Error & Mean & Std Error \\
\hline \multicolumn{5}{|l|}{ Per capita cost, \$/annual earnings } \\
\hline All & 0.00111 & $(.00014)$ & 0.00111 & $(.00014)$ \\
\hline Do Purchase incremental coverage (dep var=1) & 0.00155 & $(.00021)$ & 0.00133 & $(.00017)$ \\
\hline Do not purchase incremental coverage (dep var $=0$ ) & 0.00036 & $(.00013)$ & 0.00023 & $(.00016)$ \\
\hline Relative premium, \$/annual earnings & 0.00124 & $(1.09 \mathrm{E}-06)$ & 0.00154 & $(1.95 \mathrm{E}-07)$ \\
\hline
\end{tabular}

Notes: The above table displays the demand and cost estimates. Panel A columns (1) and (2) display the results of estimating a linear demand specification for Plan H coverage, without individual fixed-effects (column 1) and with individual fixed-effects (column 2). For comparison, Panel A columns (3) and (4) display estimates of the demand for Plan M coverage (relative to Plan L coverage). The bootstrapped standard error on the mean implied willingness-to-pay for the incremental coverage (relative to annual earnings) is calculated using 10,000 bootstrap samples. Panel B displays the mean cost estimates for everyone and separately for those who do and do not purchase the plan corresponding to each column. The mean cost reported here is the mean present discounted value of disability claim costs relative to annual earnings scaled to represent a $10 \%$ replacement rate. For reference, the relative premium for the plan corresponding to each column is listed below the mean cost estimates. 
Table A5: Additional Robustness Analysis

\begin{tabular}{|c|c|c|c|c|c|c|c|c|}
\hline \multicolumn{9}{|c|}{ Panel A: Lower Bound on Value of Public Coverage Based on Alternative Specifications } \\
\hline & \multicolumn{4}{|c|}{ Lower Bound on Mean WTP } & \multicolumn{4}{|c|}{ Lower Bound on Per-Capita Welfare } \\
\hline & \multirow{2}{*}{\multicolumn{2}{|c|}{$\begin{array}{l}\text { relative to annual } \\
\text { earnings } \\
\text { (1) }\end{array}$}} & \multirow{3}{*}{$\begin{array}{c}\% \text { of mean cost } \\
(2)\end{array}$} & \multirow{3}{*}{$\begin{array}{c}\text { scaled by } 65 \mathrm{~K} \\
\text { (3) }\end{array}$} & \multirow{2}{*}{\multicolumn{2}{|c|}{$\begin{array}{l}\text { relative to annual } \\
\text { earnings } \\
\text { (4) }\end{array}$}} & \multirow{3}{*}{$\begin{array}{c}\% \text { of mean cost } \\
\text { (5) }\end{array}$} & \multirow{3}{*}{$\begin{array}{c}\text { scaled by } 65 \mathrm{~K} \\
(6) \\
\end{array}$} \\
\hline & & & & & & & & \\
\hline & Est & Std Err & & & Est & Std Err & & \\
\hline 1. Baseline & 0.01053 & 0.00110 & $279 \%$ & 684 & 0.00677 & 0.00119 & $179 \%$ & 440 \\
\hline \multicolumn{9}{|l|}{ Robustness to Alternative Cost Measures } \\
\hline 2. Alternative Cost Measure, truncated at five years & 0.01053 & 0.00110 & $430 \%$ & 684 & 0.00817 & 0.00112 & $334 \%$ & 531 \\
\hline 3. Alternative Cost Measure, discounted at $2 \%$ & 0.01053 & 0.00110 & $222 \%$ & 684 & 0.00600 & 0.00126 & $126 \%$ & 390 \\
\hline 4. Alternative Cost Measure, discounted at $6 \%$ & 0.01053 & 0.00110 & $265 \%$ & 684 & 0.00673 & 0.00119 & $170 \%$ & 437 \\
\hline \multicolumn{9}{|l|}{ Robustness to Using Plan M Demand (instead of Plan H) } \\
\hline 5. Plan M Demand & 0.01636 & 0.09402 & $416 \%$ & 1,063 & 0.01259 & 0.09403 & $320 \%$ & 818 \\
\hline \multicolumn{9}{|c|}{ Panel B: Parameter Estimates from Alternative Specifications } \\
\hline & \multicolumn{6}{|c|}{ Demand } & \multicolumn{2}{|c|}{ Mean Cost } \\
\hline & \multicolumn{3}{|c|}{ Relative Premium } & \multicolumn{3}{|c|}{ Constant } & & \\
\hline & \multicolumn{2}{|c|}{$\begin{array}{l}\text { Coeff } \\
\text { (1) }\end{array}$} & $\begin{array}{c}\text { Std Err } \\
\text { (2) }\end{array}$ & $\begin{array}{l}\text { Coeff } \\
\text { (3) }\end{array}$ & \multicolumn{2}{|c|}{$\begin{array}{c}\text { Std Err } \\
(4)\end{array}$} & $\begin{array}{c}\text { Mean } \\
(5)\end{array}$ & $\begin{array}{l}\text { Std Err } \\
(6)\end{array}$ \\
\hline 1. Baseline & \multicolumn{2}{|c|}{-71.26} & $(11.77)$ & 0.72 & \multicolumn{2}{|c|}{$(0.026)$} & 0.00111 & $(.00014)$ \\
\hline \multicolumn{9}{|l|}{ Robustness to Alternative Cost Measures } \\
\hline 2. Alternative Cost Measure, truncated at five years & \multicolumn{2}{|c|}{-71.26} & (11.77) & 0.72 & \multicolumn{2}{|c|}{$(0.026)$} & 0.00069 & $(.0001)$ \\
\hline 3. Alternative Cost Measure, discounted at $2 \%$ & \multicolumn{2}{|c|}{-71.26} & (11.77) & 0.72 & \multicolumn{2}{|c|}{$(0.026)$} & 0.00134 & $(.00021)$ \\
\hline 4. Alternative Cost Measure, discounted at $6 \%$ & \multicolumn{2}{|c|}{-71.26} & $(11.77)$ & 0.72 & \multicolumn{2}{|c|}{$(0.026)$} & 0.00112 & $(.00017)$ \\
\hline \multicolumn{9}{|l|}{ Robustness to Using Plan M Demand (instead of Plan H) } \\
\hline 5. Plan M Demand & \multicolumn{2}{|c|}{-91.19} & (38.3) & 0.95 & \multicolumn{2}{|c|}{$(0.060)$} & 0.00111 & $(.00014)$ \\
\hline
\end{tabular}

Notes: This table displays additional robustness analysis (beyond that displayed in Table 6). Panel A displays the implied lower bound on the value of public coverage based on the alternative specifications (analogous to that reported in Table 5 Panel A row 2); Panel B displays the underlying demand and mean cost estimates. As discussed in the text, the mean cost reported here is the mean present discounted value of disability claim costs relative to annual earnings scaled to represent a $10 \%$ replacement rate. Panel A reports bootstrapped standard errors using 10,000 bootstrap samples. Each row represents the results of a distinct specification. For reference, row (1) displays the baseline estimates (from Table 4 column 1) and implied welfare bounds (from Table 5 Panel A row 2). Rows (2) through (4) display the estimates and implied welfare bounds using alternative specifications of the cost measure. The baseline analysis uses the present discounted value of costs using a $4 \%$ interest rate in this discounting, where we use the maximum potential duration for spells censored at five years (as described in the text). Row (2) displays an alternative specification where costs are measured only through the first five years (the years for which we have claims data); rows (3) and (4) display specifications where costs are defined as the present discounted value of the maximum potential duration for truncated spells, using alternative discount rates. Row (5) displays an alternative specification that relies on the less precise Plan M demand estimates (rather than the baseline Plan $\mathrm{H}$ demand estimates) to value disability insurance. 